\title{
Serum and tissue proteomic signatures of patients with hepatocellular carcinoma using 2-D gel electrophoresis
}

\author{
HUIFANG PENG $^{1 *}$, ZHIJIAN YAN $^{2 *}$, XINHUA ZENG $^{3}$, SHENG ZHANG $^{4}$, \\ HONGWEI JIANG ${ }^{1}$, HEQING HUANG ${ }^{3}$ and HUIQIN ZHUO ${ }^{5}$
}

\author{
${ }^{1}$ Department of Endocrinology, The First Affiliated Hospital and College of Clinical Medicine of \\ Henan University of Science and Technology, Luoyang, Henan 471000; ${ }^{2}$ Department of Urology, \\ The Affiliated Zhongshan Hospital; ${ }^{3}$ State Key Laboratory of Stress Cell Biology, School of Life Science; \\ ${ }^{4}$ Fujian Provincial Key Laboratory of Chronic Liver Disease and Hepatocellular Carcinoma, \\ The Affiliated Zhongshan Hospital; ${ }^{5}$ Department of Gastrointestinal Surgery, \\ Zhongshan Hospital, Xiamen University, Xiamen, Fujian 361004, P.R. China
}

Received August 16, 2018; Accepted April 24, 2019

DOI: $10.3892 / \mathrm{mmr} .2019 .10311$

\begin{abstract}
Hepatocellular carcinoma (HCC) accounts for $\sim 85 \%$ of primary liver cancer cases and is a leading cause of mortality worldwide. Effective early diagnosis is difficult for HCC; however, effective biomarkers may be beneficial for diagnosis. In the current study, serum samples, and HCC and adjacent tissue samples were obtained from patients with HCC for the detection of biomarkers using 2-D gel electrophoresis (2-DE) and matrix-assisted laser desorption/ionization-time of flight (TOF)/TOF mass spectrometry. The crude serum samples did not need to be prepared for removal of high abundance proteins. The mRNA expression levels of HCC-associated proteins were detected in tissues using reverse transcription-quantitative PCR. Statistical analysis and database matching were used to identify the differentially expressed proteins detected in the serum and tissue groups. Immunohistochemistry (IHC) was performed to detect the expression of significant proteins in HCC and adjacent tissues. The results revealed $\sim 800$ protein spots on a 2-DE gel that were detected in serum samples, and 1,200 spots were identified in the tissue samples. The
\end{abstract}

Correspondence to: Professor Huiqin Zhuo, Department of Gastrointestinal Surgery, Zhongshan Hospital, Xiamen University, Building 6, 201-209 Hubin South Road, Xiamen, Fujian 361004, P.R. China

E-mail: zhuohuiqin@xmu.edu.cn

Professor Heqing Huang, State Key Laboratory of Stress Cell Biology, School of Life Science, Xiamen University, Huangchaoyang Building, 1 Xiangan South Road, Xiamen, Fujian 361004, P.R. China E-mail: hqhuang@xmu.edu.cn

\section{*Contributed equally}

Key words: hepatocellular carcinoma, serum, proteome, 2-D gel electrophoresis protein and mRNA expression levels of oxysterol binding protein-like 11 (OSBPL11) in HCC serum and tissue samples were consistent. Pathway analysis demonstrated that members of the apolipoprotein family, particularly apolipoprotein E (APOE), and RAS family members were closely associated in HCC, either directly or via ferratin heavy polypeptide 1 . IHC results demonstrated that the APOE protein serves an important role in liver cancer development. The lysis buffer used in the current study was effective for serum protein separation in 2-DE sample preparation. In addition, the present study revealed that downregulated OSBPL11 may be a potential indicator for HCC, and the apolipoprotein family, particularly APOE, and the RAS family may cooperatively serve an important role.

\section{Introduction}

HCC is the most common type of hepatic malignancy, has a poor prognosis and accounts for $\sim 85 \%$ of primary liver cancer cases, with a 5-year survival rate of $<10 \%$. The early stages of HCC lack visible symptoms; however, there is rapid growth of the tumor (1-3). Late diagnosis and limited treatment options explain the low survival rate of patients with $\mathrm{HCC}$, while early diagnosis using effective biomarkers could improve the survival rate and therapeutic options. A total of three major types of molecular marker are used for HCC diagnosis, including serological markers, cancer stem cell markers and tumor tissue markers (4). The discovery of biomarkers present in the serum and plasma may be beneficial for a number of diseases (5), as serological markers are the most commonly used in the clinic. In addition, it may be useful to combine serum and tissue proteomics for the detection of disease.

In serum, the presence of high-abundance proteins (HAPs), including albumin, IgG, transferrin and anti-trypsin, can make it difficult to separate low-abundance proteins (LAPs) using 2-D gel electrophoresis (2-DE) for proteomic analysis (6). The detection of LAPs and peptides is typically hindered by the presence of HAPs, including albumin and IgG (7). Proteomic analysis of human serum, particularly for LAPs, has great 
potential for disease diagnosis (8). However, the majority of potential biomarkers are LAPs and must be separated from major serum proteins in order to be resolved and identified.

The present study prepared a lysis buffer to improve the resolution of protein separation using 2-DE from the serum of patients with $\mathrm{HCC}$, which removes the requirement for the depletion of HAPs. HCC tissue samples and corresponding adjacent tissue samples obtained during surgery were used to detect the expression of proteins with 2-DE and matrix-assisted laser desorption/ionization (MALDI)-time of flight (TOF)/TOF mass spectrometry (MS). Reverse transcription-quantitative PCR (RT-qPCR) was employed to evaluate the changes in the corresponding mRNA expression levels in tissues. Immunohistochemistry (IHC) was performed to detect the expression of proteins of interest in HCC and adjacent tissue samples. Statistical analysis and database matching were used to identify the differentially expressed proteins detected in the serum and tissue samples.

\section{Materials and methods}

Ethical procedures. The current study was approved by the Ethics Committee of Zhongshan Hospital. Human blood samples for the control (CS) group were collected from healthy volunteers $(n=50)$ who had no obvious signs of disease, as determined by clinical hematology. In the CS group there were 38 males and 12 females, between 45 and 75 years of age. Blood samples for the HCS group were collected from patients with HCC $(n=50)$ who were diagnosed by pathology. In the HCS group there were also 38 males and 12 females, the age range was the same as in the CS group (Table SI). Samples of HCC (HCT group) and adjacent tissue (AT group) $(n=10)$, and histological sections, were supplied by the Hepatocellular Carcinoma Clinical Sample Library (Zhongshan Hospital, Xiamen University). The samples were collected between June 2015 and June 2016. Individuals provided informed consent to participate in the study, according to the requirements of the Ethics Committee of Zhongshan Hospital. Clinical data for the HCC patients involved in the present study are shown in Tables SI and SII.

Chemicals. The current study used carrier ampholyte ( $\mathrm{pH} 5-8$; GE Healthcare), dithiothretol (DTT), 3-[(3-cholamidopropyl) dimethylammonio]-1-propanesulfonate (CHAPS) and $\alpha$-cyano-4-hydroxy cinnamic acid (HCCA) were purchased from Sigma-Aldrich; Merck KGaA. Trypsin was obtained from Promega Corporation. The new lysis buffer (lysis buffer $\mathrm{N}$ ) was composed of $7 \mathrm{M}$ urea, $4 \%$ (w/v) CHAPS, 2 M thiourea, $60 \mathrm{mM}$ DTT, $10 \mathrm{mM}$ Tris, $1 \mathrm{mM}$ EDTA, $0.5 \%$ (v/v) carrier ampholyte (pH 5-8) and $1 \%$ protease inhibitor. The lack of SDS was the principal difference from traditional lysis buffer.

Sample preparation. A total of $0.2 \mathrm{ml}$ serum from the CS and HCS groups was collected from volunteers and mixed to identify differential proteins among individuals for proteome separation. An ice-cold mixture serum sample (20 $\mu \mathrm{l}$ serum from each volunteer mixed to $1 \mathrm{ml}$ for detection) was mixed with $9 \mathrm{ml}$ lysis buffer $\mathrm{N}$, stored overnight at $-70^{\circ} \mathrm{C}$, then thawed and centrifuged at $6,000 \mathrm{xg}$ for $30 \mathrm{~min}$ at $4^{\circ} \mathrm{C}$. The protein concentration of the supernatants was determined using the
Bradford method and the samples were then stored at $-70^{\circ} \mathrm{C}$ prior to 2-DE.

Tissue samples for the HCT and AT groups, containing a mixture of $50 \mathrm{mg}$ from each sample for the different groups, were homogenized in lysis buffer $\mathrm{N}$ and placed on ice for $2 \mathrm{~h}$ prior to centrifugation at $10,000 \times \mathrm{g}$ for $30 \mathrm{~min}$ at $4^{\circ} \mathrm{C}$. The supernatants were collected and stored at $-70^{\circ} \mathrm{C}$ following determination of the protein concentration.

2-DE and imaging analysis. A high-resolution 2-DE method for separating serum and tissue proteins was performed using the Investigator 2-D Gel system (PerkinElmer, Inc.). The protein sample $(150 \mu \mathrm{g})$ for each group was loaded on a 14-cm isoelectric focusing strip for the first-dimension electrophoresis, which was performed at a total of $11,000 \mathrm{~V}$ via the following stepwise increases: $200 \mathrm{~V}$ for $0.25 \mathrm{~h}$; $300 \mathrm{~V}$ for $0.5 \mathrm{~h} ; 400 \mathrm{~V}$ for $1 \mathrm{~h}$; and $600 \mathrm{~V}$ for $16 \mathrm{~h}$. Prior to PAGE, the gel strips were equilibrated for $15 \mathrm{~min}$ in equilibration buffer (6 $\mathrm{M}$ urea, 30\% glycerol, $50 \mathrm{mM}$ Tris- $\mathrm{HCl}, 2 \% \mathrm{SDS}$ and $1 \%$ DTT) and then for $15 \mathrm{~min}$ in the same buffer containing $2.5 \%$ iodoacetamide instead of DTT. SDS-PAGE (T=12\%) for the second-dimension electrophoresis was performed at $15 \mathrm{~mA}$ per gel for $\sim 5 \mathrm{~h}$. For each group, three experimental replicates were subjected to 2-DE.

The silver-stained gels were scanned using the Image Scanner II apparatus (GE Healthcare). ImageMaster 2D Platinum software (version 7.0; GE Healthcare) was employed for digital analysis of the protein spots. Protein spots were detected and compared between the CS and HCS groups, and the HCT and AT groups, and individual spot volume values were obtained, according to the manufacturer's protocol.

In-gel digestion and MALDI-TOF/TOF MS analysis. The differentially expressed proteins were manually excised from the 2-DE gels. Each protein was washed at room temperature with $50 \mu \mathrm{l}$ Milli-Q water, twice for $20 \mathrm{~min}$ each time. The protein was then immersed in destaining solution [30 $\mathrm{mM}$ $\mathrm{K}_{3} \mathrm{Fe}(\mathrm{CN})_{6}$ and $100 \mathrm{mM} \mathrm{Na} \mathrm{S}_{2} \mathrm{O}_{3}$ at a 1:1 ratio] for $2 \mathrm{~min}$ and washed at room temperature with $100 \mu 1 \mathrm{NH}_{4} \mathrm{HCO}_{3}(25 \mathrm{mM})$ containing $50 \%$ acetonitrile (ACN), twice for $20 \mathrm{~min}$ each time. Subsequently, the gel spots were dehydrated using $100 \%$ ACN for $10 \mathrm{~min}$, dried in a vacuum centrifuge for $10 \mathrm{~min}$, and rehydrated with 10-20 $\mu$ l trypsin solution in an ice-bath for $30 \mathrm{~min}$, followed by incubation at $37^{\circ} \mathrm{C}$ for $16 \mathrm{~h}$. The supernatant was collected in new tubes, and the extracts were pooled and dried in a vacuum centrifuge (Eppendorf). Finally, $2.5 \mu \mathrm{l}$ $0.5 \%$ trifluoroacetic acid (TFA) dissolved in $60 \%$ ACN was added to each protein sample to dissolve the protein powder for MALDI-TOF/TOF MS analysis.

Each protein solution was mixed with matrix solution (HCCA saturated in $60 \% \mathrm{ACN}$ and $0.1 \%$ TFA) at a $1: 1$ ratio. The mixture $(1 \mu \mathrm{l})$ was then spotted onto the MALDI target and analyzed using a REFLEX III MALDI-TOF/TOF MS system (Bruker Corporation). The peptide spectra were recorded in the reflector mode and calibrated with acidic peptides [residues 26; $\left.\mathrm{M}\left(\mathrm{H}^{+}\right)=2,961.5\right]$ and angiotensin I (1,296.5 Da). The accuracy of the molecular ion mass was $> \pm 0.1 \mathrm{Da}$ up to a mass of 6,000 Da. All other settings were as previously published (9). Peptide mass fingerprinting (PMF) of selected proteins was performed using the MASCOT database (http://www. 
matrixscience.com/search_form_select.html). The maximum tolerance for masses was adjusted to $40 \mathrm{ppm}$ by internal calibration. Mr and $\mathrm{pI}$ values of the analyzed spots were obtained from the 2-DE gel. The SWISS-PROT (https://www.expasy. org/) databases were used for the identification of significant proteins.

Gene expression analysis. TRIzol ${ }^{\circledR}$ reagent (Thermo Fisher Scientific, Inc.) was used to extract RNA from the HCC tissue samples and adjacent tissue samples. Complementary DNA was obtained using the Takara PrimeScript ${ }^{\mathrm{TM}}$ RT-qPCR kit (Takara Bio, Inc.) as follows: $65^{\circ} \mathrm{C}$ for $5 \mathrm{~min}$, rapid cooling on ice, $30^{\circ} \mathrm{C}$ for $10 \mathrm{~min}, 42^{\circ} \mathrm{C}$ for $45 \mathrm{~min}, 95^{\circ} \mathrm{C}$ for $5 \mathrm{~min}$ and cooling on ice. RT-qPCR was performed with the SYBR ${ }^{\circledR}$ Premix Ex Taq ${ }^{\mathrm{TM}}$ II (Perfect Real Time) kit (Takara Bio, Inc.), according to the manufacturer's protocol. The housekeeping gene $\beta$-actin was used as the internal control. The primers used in the current study are listed in Table I. RT-qPCR was performed using an Applied Biosystems FAST 7500 real-time PCR system (Thermo Fisher Scientific, Inc.) with the following steps: Amplification was initiated with pre-denaturing at $95^{\circ} \mathrm{C}$ for $30 \mathrm{sec}$, denaturing was performed at $95^{\circ} \mathrm{C}$ for $5 \mathrm{sec}$, annealing and extension were performed at $62^{\circ} \mathrm{C}$ for $35 \mathrm{sec}$ over 40 cycles during the second stage, and there was a final stage of $60-95^{\circ} \mathrm{C}$ to determine the dissociation curves of the amplified products. The $2^{-\Delta \Delta \mathrm{Cq}}$ method (10) was employed to perform the analysis of differential gene expression. A Student's t-test was used for statistical analysis.

IHC. IHC staining was performed on $4 \mu \mathrm{m}$-thick HCC tissue sections and adjacent tissue sections. The slides were rehydrated in dimethylbenzene and a descending alcohol series. After washing three times with double distilled $\mathrm{H}_{2} \mathrm{O}$, citrate buffer $(0.01 \mathrm{~mol} / \mathrm{liter}, \mathrm{pH} 6.0)$ was used for antigen retrieval by boiling $\left(\geq 95^{\circ} \mathrm{C}\right)$ the slides in a microwave oven for $10 \mathrm{~min}$, after natural cooling to room temperature, slides were washed twice using double distilled $\mathrm{H}_{2} \mathrm{O}$ and twice using PBS buffer at room temperature. Then $10 \%$ BSA (Sigma-Aldrich; Merck $\mathrm{KGaA}$ ) blocking solution was used and incubated for $30 \mathrm{~min}$ at $37^{\circ} \mathrm{C}$. Apolipoprotein E (APOE) rabbit monoclonal antibody (cat. no. CY5573; Abways Technology, Inc.) was applied at 1:100 in PBS for $2 \mathrm{~h}$ at room temperature. A universal secondary antibody (EnVision ${ }^{\mathrm{TM}}+$ /HRP rabbit/mouse; DAKO; Agilent Technologies, Inc.) was then applied for $30 \mathrm{~min}$ at $37^{\circ} \mathrm{C}$. Diaminobenzidine was used for chromogen detection. Slides were incubated with diaminobenzidine for $5 \mathrm{~min}$ at room temperature and after washing for $2 \mathrm{~min}$ with water, slides were counterstained with hematoxylin for $40 \mathrm{sec}$ and hydrochloric acid alcohol solution [70\% alcohol: $\mathrm{HCl}$ at a ratio of 100:1 (v:v)] for $2 \mathrm{sec}$ at room temperature. Dehydration was achieved using an increasing alcohol series and dimethylbenzene. Slides were sealed using neutral balsam and a coverslip. A light microscope (Diaphot 300, Nikon Corporation) was used to observe the sections after staining.

Survival analysis, pathway analysis and statistical analysis. Survival analysis of differentially expressed proteins in liver cancer was performed using the Kaplan-Meier Plotter mRNA/RNA-seq database of liver cancer (http://kmplot. com/analysis/index.php?p=background). The survival analysis was carried out using the Kaplan-Meier method on 364 patients, and hazard ratios with $95 \%$ confidence intervals and log-rank P-values were calculated. Pathway analysis of identified proteins was performed using the Search Tool for Interactions of Chemicals (STITCH; http://stitch.embl. de). The functional properties and subcellular localization of the proteins were determined using the UniProt (www. uniprot.org/) and PSORT (https://db.psort.org) databases, respectively.

The data are expressed as the mean \pm SD of triplicate experiments. Significant differences among groups were determined using one-way ANOVA with SPSS version 19 (IBM Corp.) followed by the LSD post-hoc test. $\mathrm{P}<0.05$ was considered to indicate a statistically significant difference.

\section{Results}

Differential protein profiles in serum and tissue groups. The serum sample in the lysis buffer was separated using 2-DE gel at a $\mathrm{pH}$ of $5-8$. A total of $150 \pm 5 \mu \mathrm{g}$ serum protein was considered optimal for separation using 2-DE. The new lysis buffer was conducive to obtaining more protein spots (Fig. S1). As demonstrated in Fig. $1 \mathrm{~A}$ and $\mathrm{B}, \sim 800$ proteins were visualized. Fig. 1C and D demonstrates the 2-DE results for the HCT and AT groups, in which almost 1,200 proteins were revealed by sliver staining in each tissue gel.

Quantitative image analysis based on the percentage of the spots revealed that certain proteins were either significantly upregulated or downregulated between the two groups (Fig. 2). Compared with the CS group, the expression levels of 24 proteins were significantly different in the HC group (Fig. 2A). Furthermore, 12 proteins were revealed to be differentially expressed in the AT and HCT groups (Fig. 2B).

Identification of differentially expressed proteins. MALDI-TOF/TOF MS, PMF and a database search were used to evaluate the proteins identified in Fig. 2. MALDI-TOF/TOF MS can identify small amounts of protein in 2-DE gels. The differentially expressed proteins were digested by trypsin in the gel to further assist with the identification of the proteins (Table II). Of the 24 differentially expressed proteins between the CS and HCS groups, seven were identified. Additionally, all 12 differentially expressed proteins in the AT and HCT groups were identified. Biochemical parameters based on the results of the database search are presented in Table II, including accession number, protein name, score, Mw and PI.

The ratio of protein spots compared with the whole gel and the spot grey value may demonstrate the expression level of the corresponding protein. Taking the CS or AT groups as the control, the relative intensity ratio of the HCS and HCT groups revealed significant changes in the expression levels of certain proteins, which are presented in Table II. A total of three upregulated proteins were identified (spot nos. 4, 7 and 9) and four downregulated proteins were revealed (spot nos. 4, 12, 15 and 16) in the HCS group compared with the CS group. For the tissue groups, seven upregulated proteins were identified (spot nos. 4, 5, 6, 8, 10, 11 and 12) and five downregulated proteins were revealed (spot nos. 1, 2, 3, 7 and 9) in the HCT group compared with the AT group. 


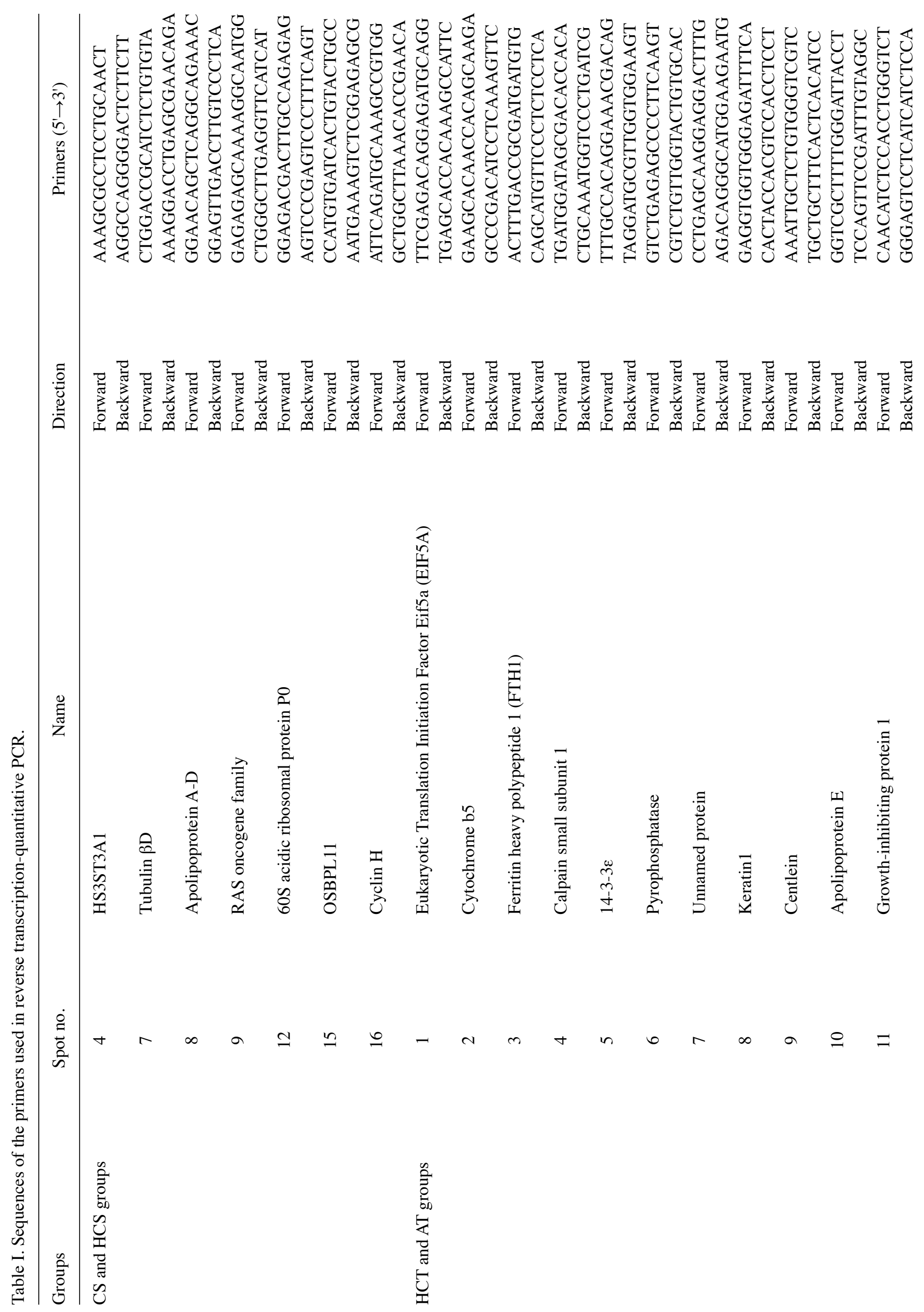


Gene expression analysis. RT-qPCR analysis was performed to assess the extent of the changes in protein expression levels in the 2-DE results. A total of seven differentially expressed genes from the CS and HCS groups, and twelve genes from the AT and HCT groups (Table II) were selected for this analysis. The gene expression levels of the proteins identified in the CS/HCS groups were analyzed in HCC tissues and corresponding adjacent tissues by RT-qPCR, and the results are demonstrated in Fig. 3A and Table SIII. The mRNA expression levels determined by RT-qPCR for ten samples of each group were relatively consistent with the protein expression levels revealed by 2-DE (Figs. 1A, B and 2A; Table II). The expression level of one gene, oxysterol binding protein-like 11 (OSBPL11), was revealed to be lower in HCC tissues compared with adjacent tissues in all 10 samples; this difference was identified to be significant in nine of the samples, and the difference between the HCT and AT groups reached a highly significant level $(\mathrm{P}<0.001$; Table SIII). This result was consistent with the results of 2-DE. In addition, the expression levels of six other genes, including heparan sulfate (glucosamine) 3-O-sulfotransferase 3A1 (HS3ST3A1), tubulin $\beta$ D, the RAS oncogene family, apolipoprotein $\mathrm{A}-\mathrm{D}, 60 \mathrm{~S}$ acidic ribosomal protein $\mathrm{P} 0$ and cyclin $\mathrm{H}$, were partly consistent with the results of 2-DE. These results further confirmed the validity of the proteomic approach for the identification of serum biomarkers in HCC.

The expression levels of 12 differentially expressed genes identified in the AT and HCT groups (Figs. 1A, B and 2; Table II), were also evaluated using RT-qPCR in a total of ten tissue samples (Fig. 3B; Table SIV). Among the 12 genes investigated, the expression levels of 11 genes were revealed to be significantly higher in the HCT group compared with the AT group. By contrast, the expression level of the APOE gene was identified to be lower in the HCT group compared with the AT group. The gene expression levels in the HCT group identified by RT-qPCR were not completely consistent with the protein changes identified by 2-DE. A total of six spots (nos. 4, 5, 6, 8, 11 and 12) demonstrated similar expression levels in 2-DE compared with RT-qPCR for the AT and HCT groups.

Subcellular localization and functional properties. As presented in Fig. 4A and Table III, the identified proteins were predominantly localized in the cytoplasm, nucleus, Golgi, endosomes, endoplasmic reticulum, lysosomes and extracellular space. The statistical analysis was not performed separately for the proteins identified in the CS/HCS groups and the AT/HCT groups. In total, $41.67 \%$ of the proteins were located the in cytoplasm, $16.67 \%$ were located in the nucleus, $12.5 \%$ in the Golgi, $8.33 \%$ in endosomes, $4.17 \%$ in lysosomes or endoplasmic reticulum, and $12.5 \%$ were identified to be located in the extracellular space as secretory proteins.

In total, the proteins were revealed to be enriched in 19 molecular function terms (Fig. 4B), including 'sulfotransferase activity', 'GTPase activity', 'ferroxidase activity', 'kinase activity', 'oxidoreductase activity', 'inorgnesium diphosphatase activity', 'ribosome binding', 'ion binding', 'GTP binding', 'RNA binding', 'U6 snRNA binding', 'lipid binding', 'protein binding', 'structural constituent of ribosome', 'structural molecule activity' and 'antioxidant'. Comprehensive analysis revealed that $63.64 \%$ of the functions were associated with protein binding, $27.27 \%$ were 

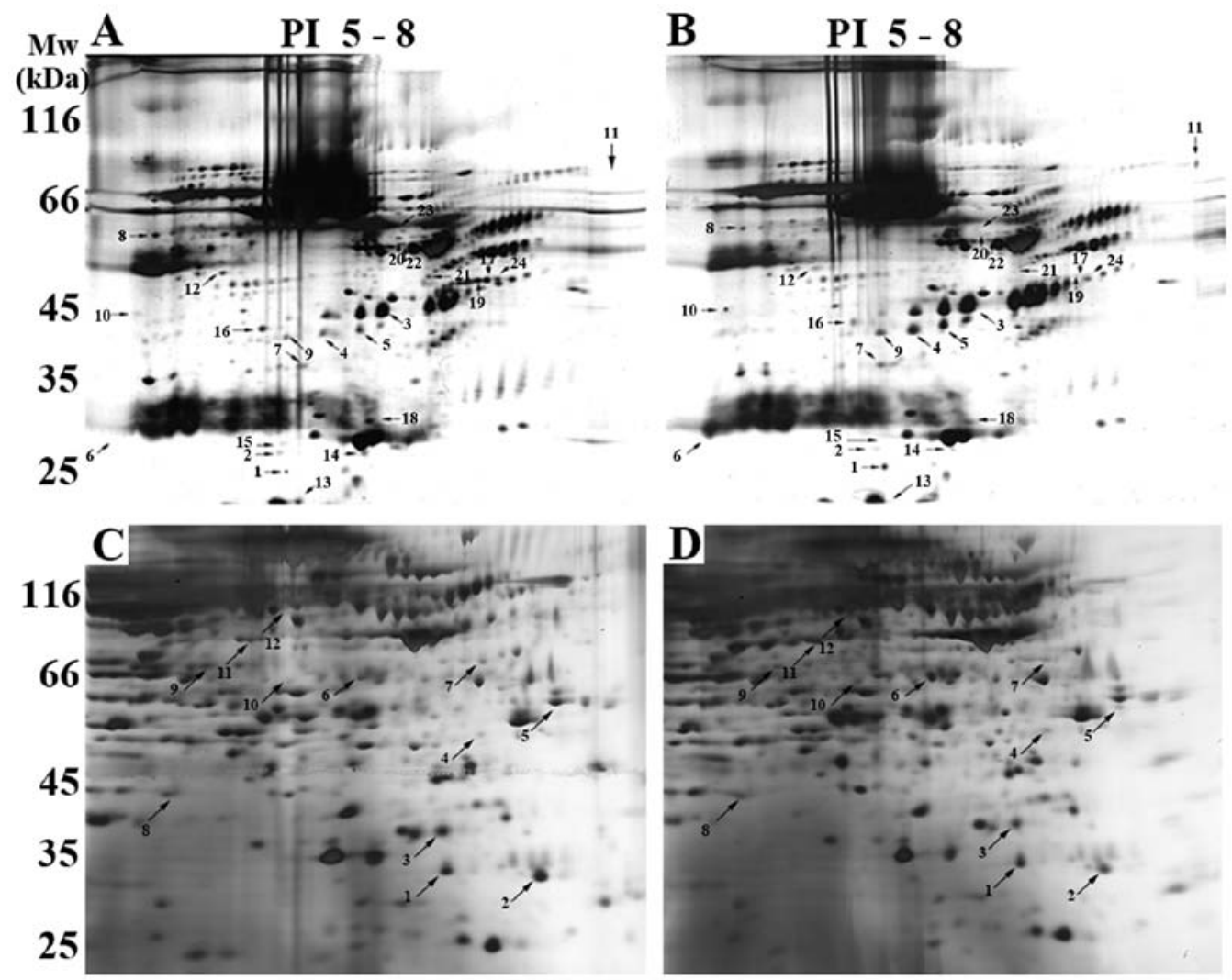

Figure 1. 2-DE images of the proteome from HCC serum and tissue samples. (A) Image of the serum from healthy individuals. (B) Image of the serum from patients with HCC. (C) Image of adjacent tissue samples obtained from patients with HCC. (D) Image of HCC tissue samples obtained from patients during surgery. A total of $150 \mu \mathrm{g}$ serum protein (1:9 ratio of serum to lysis buffer) was directly loaded onto a 2-DE gel for protein separation without depletion of high abundance proteins. The tissue protein loading quantity was also $150 \mu \mathrm{g}$. Numbered spots (indicated by arrows) correspond to the numbers in Tables I-III. 2-DE, 2-D gel electrophoresis; HCC, hepatocellular carcinoma; PI, isoelectric point.
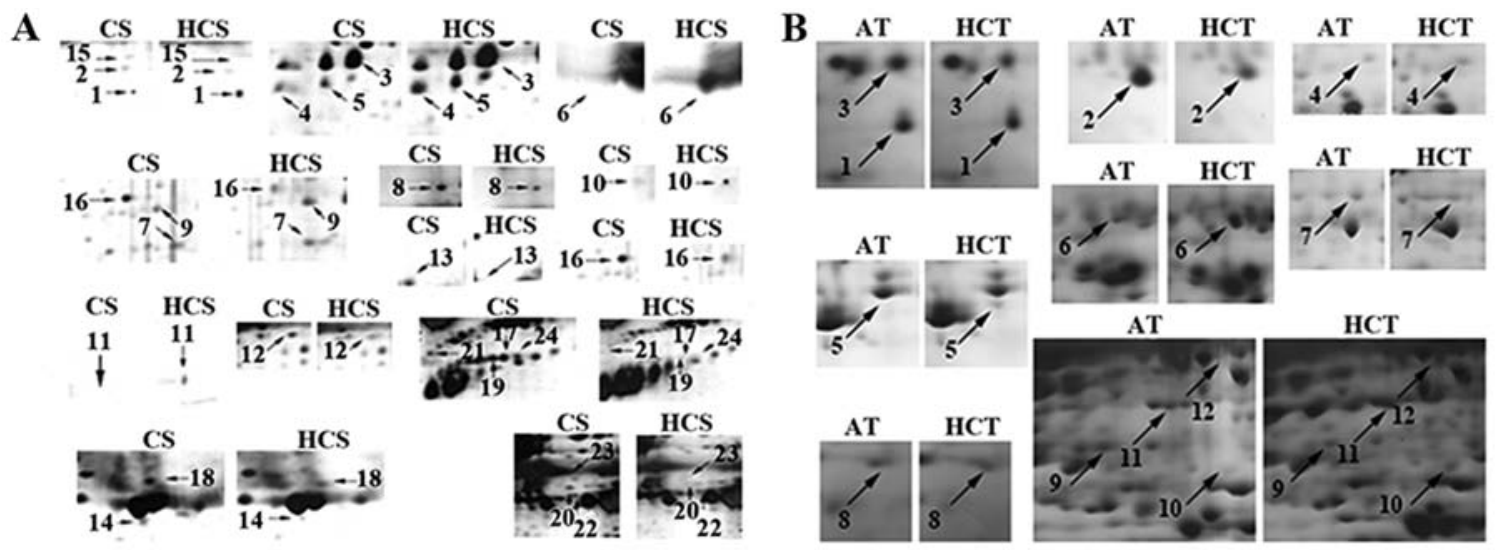

Figure 2. Comparison of the enlarged spots revealed by 2-D gel electrophoresis to identify the differentially expressed proteins. (A) Protein spots from the CS and HCS groups. (B) Protein spots from the AT and HCT groups. Numbered spots (indicated by arrows) correspond to the numbers in Tables I-III. CS, control serum; HCS, hepatocellular carcinoma serum; AT, adjacent tissue; HCT, hepatocellular carcinoma tissue.

associated with enzyme activity and $6.06 \%$ were associated with structure. The enriched biological processes varied markedly and included the following: Biosynthetic process, cell cycle, signal transduction, transport, metabolic and immune response (Table III).

Pathway analysis reveals the interaction of regulated proteins. Pathway analysis of the differentially expressed proteins in the $\mathrm{CS} / \mathrm{HCS}$ and $\mathrm{AT} / \mathrm{HCT}$ groups was performed using the STITCH database, and the protein-protein network is presented in Figs. 5 and S2; the network was not generated separately for the proteins identified in the CS/HCS groups and the AT/HCT groups. The network indicates a strong interaction among members of the RAS oncogene family and the APO family, the expression of which had been detected in HCC tissue (Fig. S2). Additionally, an association was revealed between these two families via the proteins ferritin heavy polypeptide 1 (FTH1) and RAB35. 


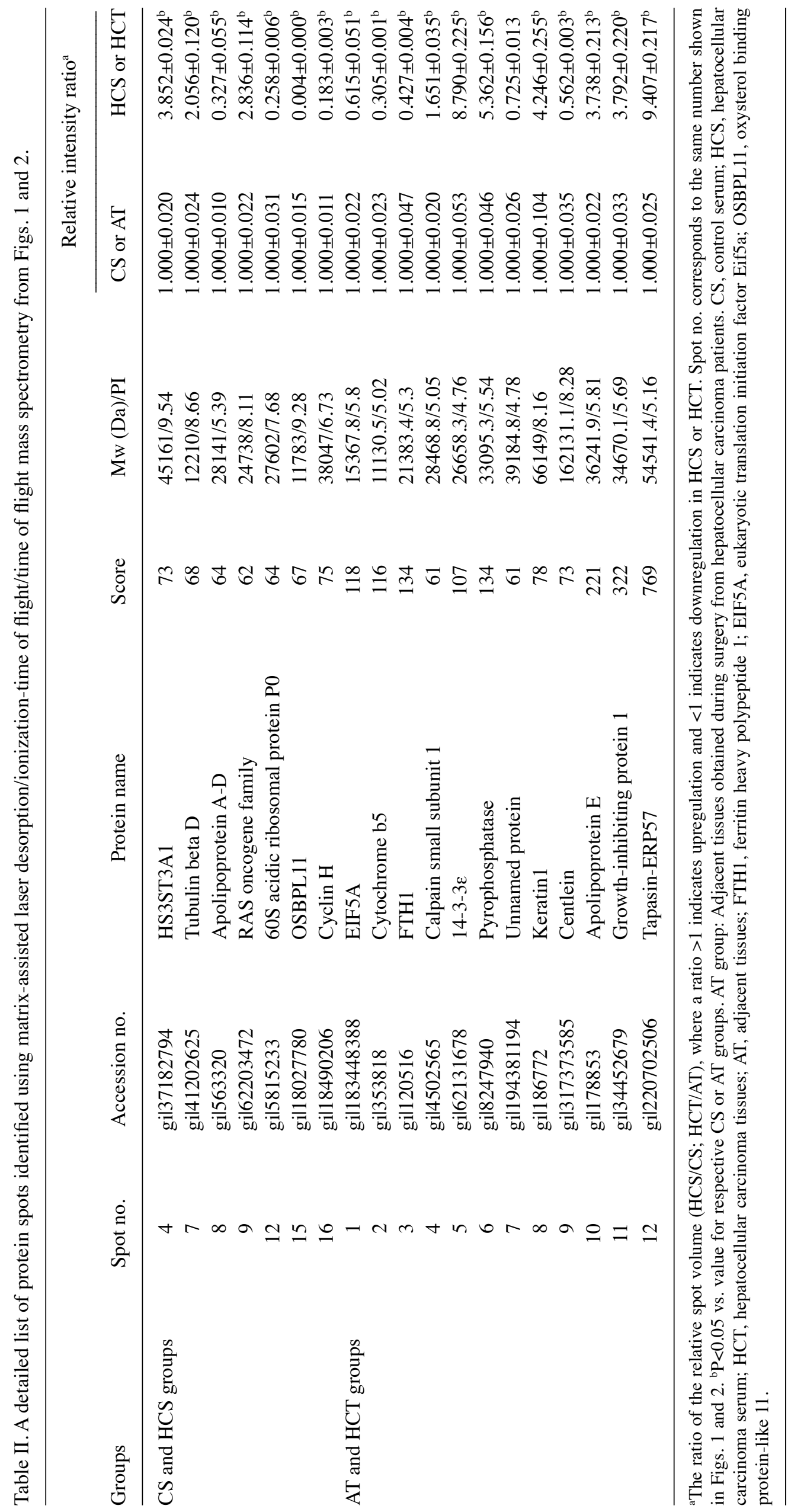



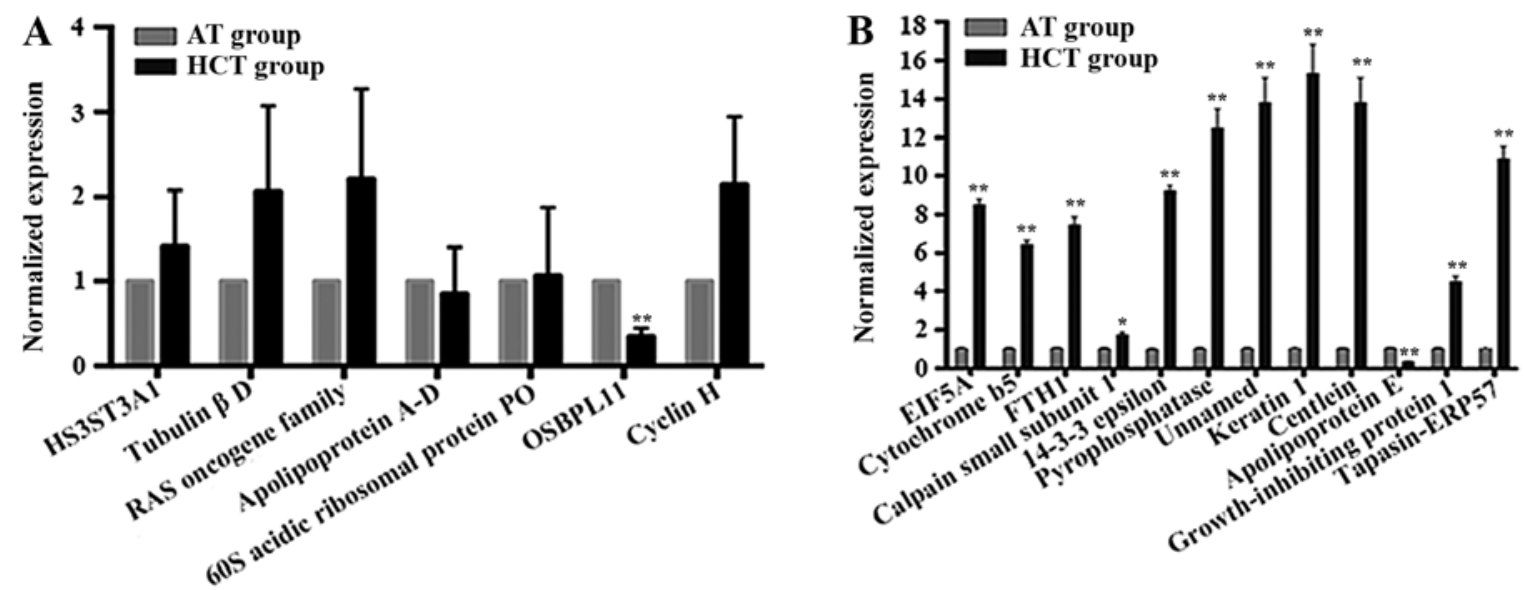

Figure 3. Gene expression levels of HCC-associated proteins in tissue samples identified from 2-DE. (A) Gene expression levels in tissue samples of HCC-associated proteins identified from serum 2-DE. (B) Gene expression levels in tissue samples of HCC-associated proteins identified from tissue 2-DE. ${ }^{*} \mathrm{P}<0.05,{ }^{* *} \mathrm{P}<0.01$ vs. respective AT group. HCC, hepatocellular carcinoma; 2-DE, 2-D gel electrophoresis; AT, adjacent tissue.

A

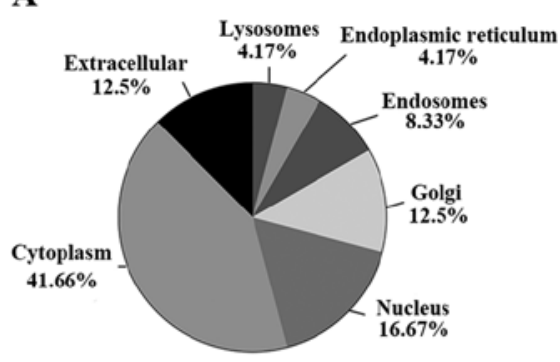

B

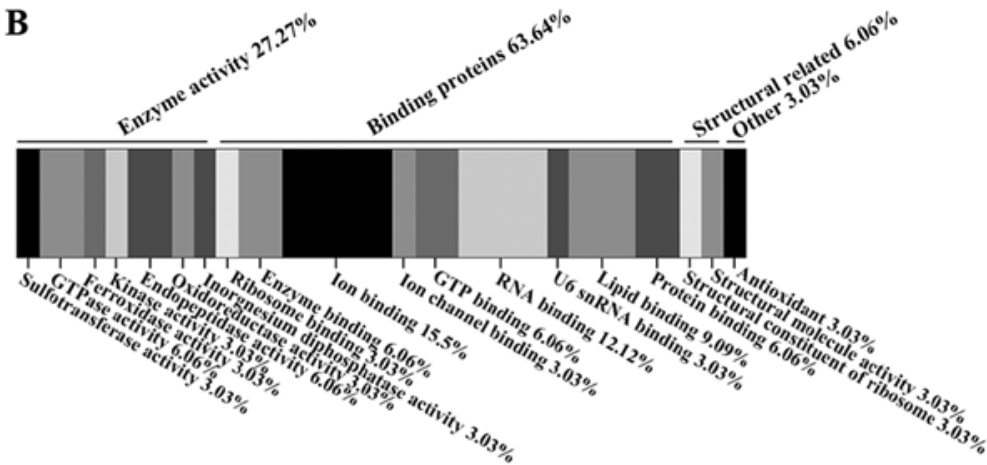

Figure 4. Subcellular locations and biological processes of the differentially expressed proteins. (A) Subcellular locations and (B) biological processes. The differentially expressed proteins were detected in serum and tissue samples, and the locations and biological processes of these proteins were predicted using the PSORT program and the UniProt database.

Survival analysis and IHC. The differentially expressed proteins OSBPL11 and APOE, detected by 2-DE, were selected to evaluate their association with survival in liver cancer (Fig. 6). Compared with a low expression level, it was revealed that high expression of OSBPL11 was associated with a higher survival probability in liver cancer. A significant difference $(\mathrm{P}=0.036)$ was identified in the 5-year survival rate for liver cancer cases with high OSBPL11 expression compared with low expression (Fig. 6A). However, no significant difference was identified for the 10-year survival rate (Fig. 6B). Furthermore, the survival rate for patients with liver cancer with a high APOE expression level was higher compared with patients with a low APOE expression level. A significant difference was identified in the 5-year survival rate $(\mathrm{P}=0.0047$; Fig. $6 \mathrm{C})$ and the 10 -year survival rate $(\mathrm{P}=0.0026$; Fig. $6 \mathrm{D})$ for patients with liver cancer with a high APOE expression level compared with patients with a low APOE expression level.

The results of IHC staining to detect APOE expression in $\mathrm{HCC}$ and adjacent tissues of different liver cancer grades are presented in Fig. 6E. The expression of APOE was higher in HCC tissues compared with corresponding adjacent tissues in samples obatined from patients with grade I-III liver cancer. Additonally, the expression level of APOE increased with increasing tumor grade, both in HCC tissues and adjacent tissue samples.

\section{Discussion}

Among all biological samples, the human serum proteome is the largest representative of the total human proteome. HAPs, including human serum albumin, account for $>75 \%$ of all proteins present in the serum and limit the resolution of MS analysis. The most common technique used for the removal of HAPs from serum samples is chromatography (11). However, potential biomarkers bound to HAPs may be removed during methods involving chromatography, including ion-exchange and affinity approaches $(6,12)$. If depletion of HAPs from crude serum samples is not performed, a number of indicators may remain in the sample, which could assist with the detection of useful protein markers. It has been reported that fragmentation of low molecular weight proteins in white blood cells can be performed by incubation with lysis buffer followed by constant-filled gel electrophoresis (13), which indicates that lysis buffer may serve an important role in improving the resolution of proteins separated from human serum samples with 2-DE. The lysis buffer used in the present study was able to disperse the interaction between LAPs and HAPs to improve the protein resolution in the gel. In addition, the lysis buffer allowed a number of LAPs to remain in the sample, which assisted with the identification of their physiological functions. 


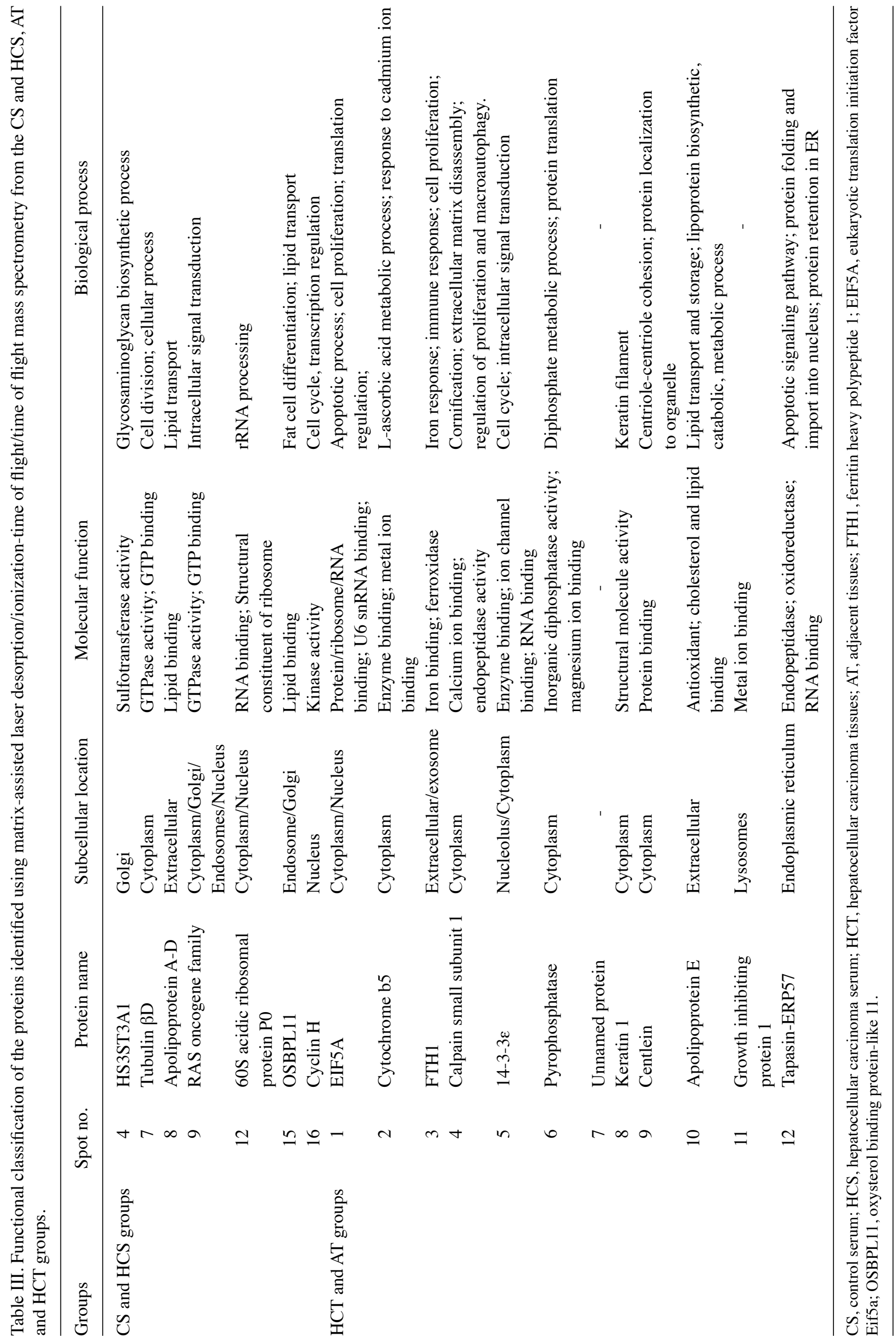




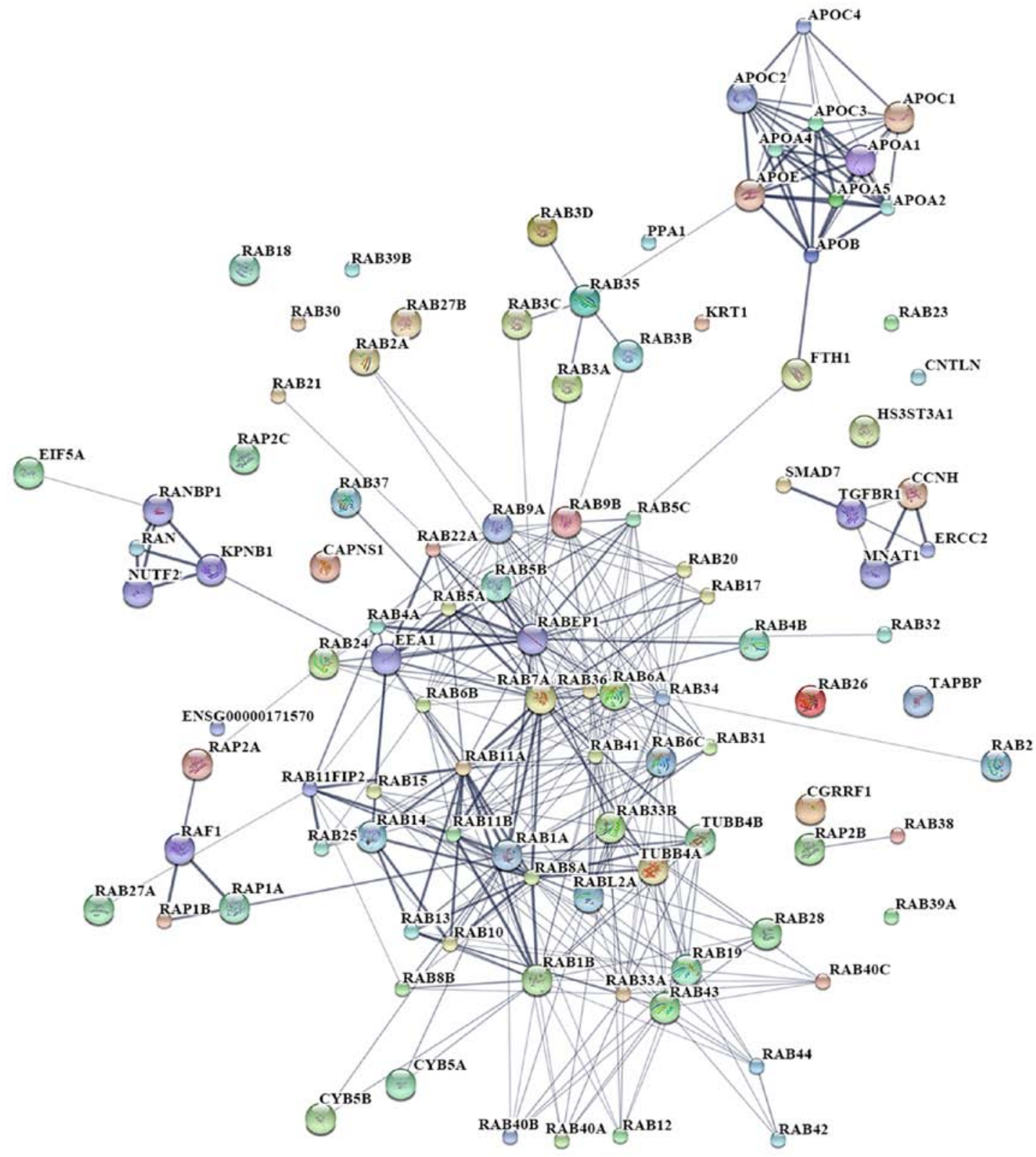

Figure 5. Pathway analysis of the differentially expressed proteins detected from the serum and tissue samples. APO, apolipoprotein; RAB, member of RAS oncogene protein family; FTH1, ferritin heavy polypeptide 1.

According to the present results, the differentially expressed proteins were identified as HS3ST3A1, tubulin $\beta \mathrm{D}$, apolipoprotein A-D, the RAS oncogene family, 60S acidic ribosomal protein P0, OSBPL11 and cyclin H. HS3ST3A1 serves an important role in vascular homeostasis, and low mRNA expression levels of HS3ST3A1 have been identified in pre-eclamptic placental tissue (14). The current results demonstrated that the protein expression level of HS3ST3A1 was upregulated in serum samples obtained from patients with $\mathrm{HCC}$, which indicates that this protein may serve a role in liver tumor vascular-associated processes.

Tubulin, a structural protein, is the target of certain antimitotic drugs, including peloruside, laulimalide and noscapine (15). In the present study, tubulin $\beta \mathrm{D}$ protein was upregulated in the serum of patients with HCC. It could be suggested this increased expression of tubulin $\beta$ D protein may provide support for cancer cell division.
A high expression level of apolipoprotein-D has been detected in high-grade prostatic intraepithelial neoplasia and prostate cancer, but not in non-malignant epithelial cells. This suggests that apolipoprotein-D may be a marker of malignant transformation in the prostate (16). In addition, apolipoprotein family members have been demonstrated to serve important roles in lipid transport and metabolism process. Abnormal hepatic fat metabolism can be a precursor of HCC. This may explain why the expression level of apolipoprotein was significantly different in serum samples obtained from patients with HCC in the current study.

The RAS family has been demonstrated to serve key roles in malignant transformation in numerous types of cancer (17). The current study revealed an increased expression level of RAS in serum, which is easily detected.

The ribosomal acidic $\mathrm{P} 0$ protein is an essential component of the eukaryotic ribosomal stalk, and P0 protein 

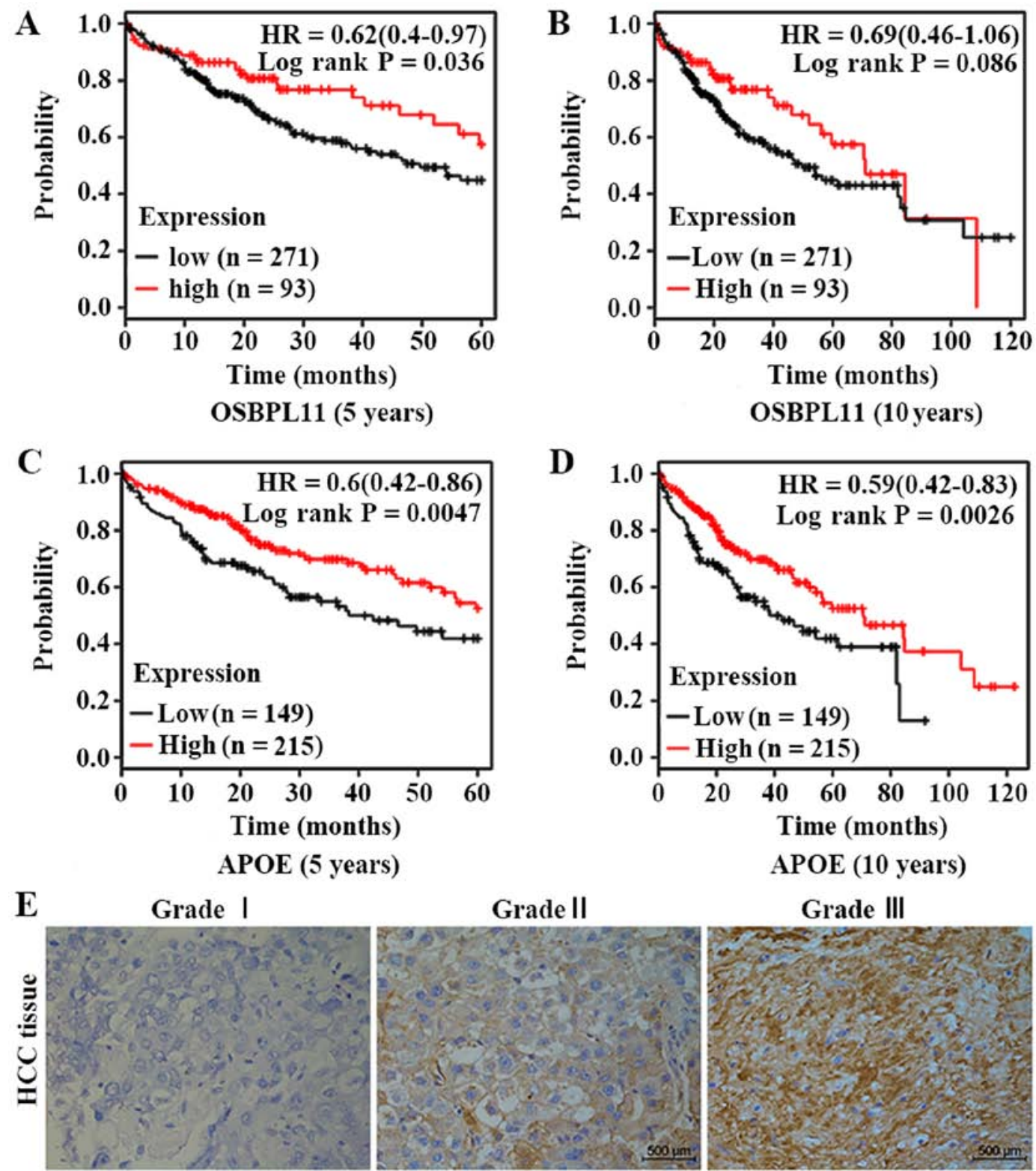

APOE (10 years)

$\mathbf{E}$
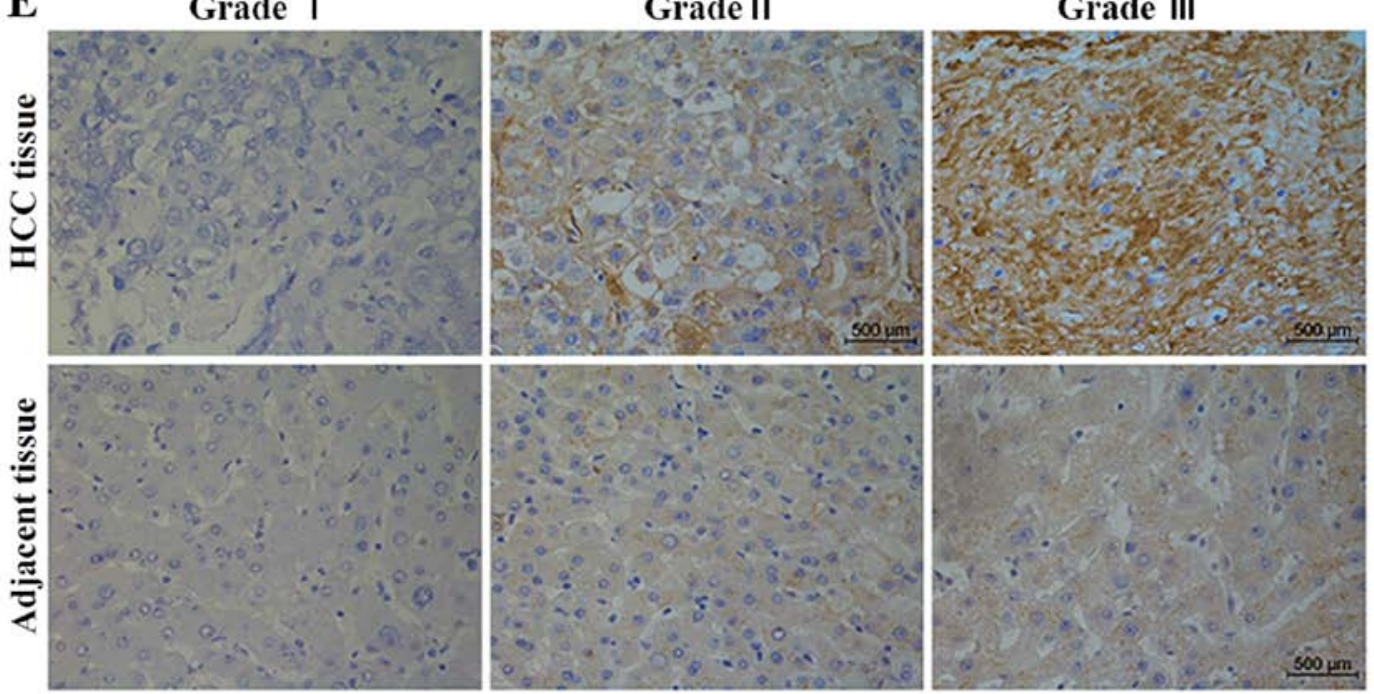

Figure 6. Survival analysis using Kaplan-Meier Plotter and the IHC results. (A) 5-year survival analysis of OSBPL11 expression levels in patients with liver cancer using the Kaplan-Meier Plotter mRNA/RNA-seq database of liver cancer. (B) 10-year survival analysis of OSBPL11 expression levels in patients with liver cancer using the Kaplan-Meier Plotter mRNA/RNA-seq database of liver cancer. (C) 5-year survival analysis of APOE expression levels in patients with liver cancer using the Kaplan-Meier Plotter mRNA/RNA-seq database of liver cancer. (D) 10-year survival analysis of APOE expression levels in patients with liver cancer using the Kaplan-Meier Plotter mRNA/RNA-seq database of liver cancer. (E) IHC results of APOE expression in hepatocellular carcinoma and adjacent tissue samples of different cancer grades (magnification, x400). IHC, immunohistochemistry; OSBPL11, oxysterol binding protein-like 11; APOE, apolipoprotein E; HCC, hepatocellular carcinoma; HR, hazard ratio.

overexpression may cause tumorigenesis in breast and liver tissues (18). However, in the serum of patients with HCC, the protein expression of $60 \mathrm{~S}$ acidic ribosomal P0 was downregulated, and the gene expression in $\mathrm{HCC}$ tissue samples was downregulated in nine out of 10 cases. However, the roles of
$60 \mathrm{~S}$ acidic ribosomal $\mathrm{P} 0$ protein and other ribosomal acidic $\mathrm{P} 0$ proteins may differ among multiple tumors.

The OSBP-associated protein family has been reported to serve a role in lipid metabolism, cell signaling and vesicle transport in cells (19). OSBPL11 likely serves a role during the late 
stages of adipogenic differentiation and possibly in the maintenance of the mature adipocyte phenotype (20). In the present study, the expression level of OSBPL11 was lower in the serum of patients with HCC compared with that in healthy controls. In addition, the mRNA expression level was lower in tumor tissue samples compared with adjacent tissue samples. Survival analysis demonstrated that the expression level of OSBPL11 in liver cancer was associated with the 5-year survival rate, but not the 10-year survival rate. This may be associated with the function of the OSBP-associated protein family, members of which are high-capacity platforms for the inter-organelle exchange of small molecules and information (21); alternatively, the OSBP-related proteins could execute multifaceted functions in sterol and sphingolipid homeostasis, post-Golgi vesicle transport, and phosphatidylinositol-4-phosphate and target of rapamycin complex 1 signaling (22). More experimental verification is required. Blood count parameters (e.g. $\alpha$-fetoprotein and protein induced by vitamin $\mathrm{K}$ absence or antagonist-II) were not obtained in the present study. The OSBP-related protein family could be involved in lipid metabolism, cell signaling and vesicle transport in cells, and OSBPL11 likely plays a role during the late stages of differentiation and possibly in the maintenance of the mature adipocyte phenotype $(19,20)$. Therefore, it was hypothesized that OSBPL11 may have an important relationship with HCC, and the high expression of OSBPL11 in liver cancer may serve an important role in the early stages of patient survival, although this needs further research to confirm.

Using IHC and RT-qPCR, cyclin H has been demonstrated to be overexpressed in 219 tumor samples, and was revealed to interact with p53, cyclin-dependent kinase 7 and MNAT1 component of CDK activating kinase (23). However, in the present study, the expression level of cyclin $\mathrm{H}$ was downregulated in HCC serum samples. The reason for this difference between serum and tissue samples remains unclear.

A number of differentially expressed proteins were identified in HCC tissues compared with adjacent tissues. Eukaryotic translation initiation factor Eif5a (EIF5A), a translation factor, has functions in both initiation and elongation, and serves a role in the regulation of cell proliferation and apoptosis. An increased expression level of EIF5A has been demonstrated to be a cancer biomarker and is associated with a poor prognosis in a number of cancer types $(24,25)$. However, the current results demonstrated that EIF5A was downregulated in HCC tissues compared with adjacent tissues. The proliferation and apoptosis of HCC cells in the present study were not evaluated; therefore, the association between the EIFA expression level and the cellular conditions could not be evaluated.

The cytochrome b5 (Cyb5) expression level is an important determinant of in vivo drug responses, including currently prescribed anticancer agents (26). Differences in Cyb5 expression could be a significant determinant of the rates of drug disposition in humans (27). The differential expression level of Cyb5 protein in tumor tissues might be associated with anticancer drug treatment, which was not taken into account during sample collection.

Tumor cells of different molecular subtypes can be characterized by changes in the balance of intracellular ions and certain associations; ferritin can serve an important role in this process (28). It has been demonstrated that increased iron in breast cancer cells caused by upregulation of ferritin expression could protect the cells from natural killer cell-mediated cytolysis (29). In the present study, FTH1 was detected at a lower level in HCC tissues compared with adjacent tissues, indicating that the process of iron metabolism changes in cancer cells.

Calpain small subunit 1 had been identified to contribute to HCC growth and metastasis. The expression level of calpain small subunit 1 has been revealed to be higher in highly metastatic HCC cell lines and in HCC tumor tissues compared with healthy tissues (30); the present results were consistent with this previous study. In the current study, calpain small subunit 1 was upregulated in HCC tissues compared with the corresponding adjacent tissue, suggesting that the HCC cells were rapidly growing and metabolizing.

A significantly lower protein expression level of $14-3-3 \varepsilon$ has been revealed in gastric cancer tissue samples compared with matched non-neoplastic tissue. The reduced levels of 14-3-3 $\varepsilon$ may have a role in gastric carcinogenesis (31). In the present study, the protein and gene expression levels of $14-3-3 \varepsilon$ were significantly higher in HCC tissue samples compared with adjacent tissue samples, which indicates that the regulation of metabolism is different in HCC compared with other cancer types.

Inorganic pyrophosphatase is an enzyme that had been identified to be upregulated in various types of tumors, and overexpression of pyrophosphatase has been observed in cancers of the esophagus, stomach and pancreaticobiliary system (32). The current results demonstrated that the protein and gene expression levels of pyrophosphatase were significantly upregulated in HCC tissues compared with adjacent tissues.

The upregulation of keratin 1 has been revealed to increase drug resistance in nasopharyngeal carcinoma cell lines. In addition, the protein expression level and activity level of keratin 1 are higher in cisplatin-resistant nasopharyngeal carcinoma cell lines compared with their parental cell lines (33). The current study revealed that keratin 1 was upregulated in HCC tissues, which may be associated with drug resistance.

Centlein is a microtubule-associated protein that can directly bind to purified microtubules via its longest coiled-coil domain (34). The differential protein and gene expression levels of centlein in cancer tissues compared with adjacent tissues may be caused by the microtubule proteins.

Apolipoproteins are protein constituents of lipoproteins that transport cholesterol and fat, and are central to cardiovascular health and disease. APOE overexpression can promote cancer cell proliferation and migration. Additionally, APOE overexpression may also contribute to an aggressive clinical course in patients with lung adenocarcinoma and malignant pleural effusions (35). In the present study, a number of apolipoprotein family members were identified to be differentially expressed in HCC serum samples compared with healthy controls. This suggests that the apolipoprotein family is closely associated with HCC. The survival analysis and IHC results indicate that the expression of APOE serves an important role in liver cancer development.

Tapasin is an essential adapter protein that recruits major histocompatibility complex I (MHCI) molecules for antigen processing and catalyzes peptides during loading of MHCI (36); however, to the best of our knowledge, no studies have investigated tapaisn-ERP57 in any cancer type. In the current study, tapasin-ERP57 protein expression was different in HCC tissues compared with corresponding adjacent 
tissue. Therefore, tapasin-ERP57 may serve a role in the tumor-associated immune process in HCC.

With the development of bioinformatics, numerous bioinformatics databases and software programs have been used to predict protein-protein and protein-chemical interactions. STITCH is a resource that can predict interactions of proteins and chemicals using evidence obtained from studies, databases and the literature. STITCH contains the interactions of $>2.5$ million proteins in 630 organisms, and has been used in a number of studies (9). The present study generated a protein-protein network of the differentially expressed proteins in HCC serum and tissue samples, which revealed an association between the apolipoprotein family and the RAS protein family in HCC, which, to the best of our knowledge, has not previously been reported.

A number of studies have used chromatography of crude serum samples following the removal of HAPs to identify biomarkers that may be useful for the diagnosis of cancer. However, numerous potential biomarkers bound to HAPs may be filtered out of the sample by this approach. In the current study, serum 2-DE was performed without HAP removal and the serum proteins were then effectively separated. To identify protein biomarkers, serum samples were obtained from patients with HCC and healthy controls, and HCC tissues samples and corresponding adjacent tissue samples were collected. Differential expression levels of apolipoprotein family members were detected in both the serum samples and tissue samples, indicating that apolipoprotein proteins, particularly APOE, are important in HCC. Furthermore, the expression levels of OSBPL11 appeared to have an important role in HCC. The roles of the RAS protein family and apolipoprotein family should also be considered in the development of HCC.

\section{Acknowledgements}

Not applicable.

\section{Funding}

The present study was funded by grants from the National Natural Scientific Foundation of China (grant nos. 81370048 and 30870515), the Natural Science Foundation of Fujian Province (grant nos. 2016J01631 and 2016-ZQN-88) and the Key Projects for Technology Plan of Xiamen Province in China (grant no. 3502Z20174076).

\section{Availability of data and materials}

The datasets used and/or analyzed during the current study are available from the corresponding author on reasonable request.

\section{Authors' contributions}

$\mathrm{HZ}$ and $\mathrm{HH}$ conceived and designed the research. HP, ZY, XZ and SZ developed the methodology. HP, XZ and HJ analyzed and scored the data. ZY and SZ provided administrative, technical and material support. HP and HJ wrote and reviewed the manuscript. $\mathrm{HZ}$ and $\mathrm{HH}$ supervised this study. All authors read and approved the manuscript and agree to be accountable for all aspects of the research in ensuring that the accuracy or integrity of any part of the work are appropriately investigated and resolved.

\section{Ethics approval and consent to participate}

The current study was approved by the Ethics Committee of Zhongshan Hospital. Individuals provided informed consent to participate in the study, according the requirements of the Ethics Committee of Zhongshan Hospital.

\section{Patient consent for publication}

Not applicable.

\section{Competing interests}

The authors declare that they have no competing interests.

\section{References}

1. Li S, Yang F and Ren X: Immunotherapy for hepatocellular carcinoma. Drug Discov Ther 9: 363-371, 2015.

2. McGlynn KA, Petrick JL and London WT: Global epidemiology of hepatocellular carcinoma: An emphasis on demographic and regional variability. Clin Liver Dis 19: 223-238, 2015.

3. Torre LA, Bray F, Siegel R, Ferlay J, Lortet-Tieulent J and Jemal A: Global cancer statistics, 2012: CA Cancer J Clin 65: 87-108, 2015.

4. Han L, Lv Y, Guo H, Ruan Z and Nan K: Implications of biomarkers in human hepatocellular carcinoma pathogenesis and therapy. World J Gastroenterol 20: 10249-10261, 2014

5. Ray S,Patel SK, Kumar V, Damahe J and Srivastava S: Differential expression of serum/plasma proteins in various infectious diseases: Specific or nonspecific signatures. Proteomics Clin Appl 8: 53-72, 2014.

6. Chromy BA, Gonzales AD, Perkins J, Choi MW, Corzett MH, Chang BC, Corzett $\mathrm{CH}$ and McCutchen-Maloney SL: Proteomic analysis of human serum by two-dimensional differential gel electrophoresis after depletion of high-abundant proteins. J Proteome Res 3: 1120-1127, 2014.

7. Sano S, Tagami S, Hashimoto Y, Yoshizawa-Kumagaye K, Tsunemi M, Okochi M and Tomonaga T: Absolute quantitation of low abundance plasma APL1 $\beta$ peptides at sub-fmol $/ \mathrm{mL}$ Level by SRM/MRM without immunoaffinity enrichment. J Proteome Res 13: 1012-1020, 2014.

8. Xu S, Liu P, Lu X, Zhang J, Huang L, Hua W, He D and Ouyang J: A highly sensitive 'turn-on' fluorescent sensor for the detection of human serum proteins based on the size exclusion of the polyacrylamide gel. Electrophoresis 35: 546-553, 2014.

9. Luo LZ, Jin HW and Huang HQ: Transferrin-cisplatin specifically deliver cisplatin to HepG2 cells in vitro and enhance cisplatin cytotoxicity. J Proteomics 77: 237-250, 2012.

10. Livak KJ and Schmittgen TD: Analysis of relative gene expression data using real-time quantitative PCR and the 2(-Delta Delta C(T)) method. Methods 25: 402-408, 2001.

11. Liu W, Liu B, Cai Q, Li J, Chen X and Zhu Z: Proteomic identification of serum biomarkers for gastric cancer using multi-dimensional liquid chromatography and 2D differential gel electrophoresis. Clin Chim Acta 413: 1098-1106, 2012.

12. Qin S, Ferdinand AS, Richie JP, O'Leary MP, Mok SC and Liu BC: Chromatofocusing fractionation and two-dimensional difference gel electrophoresis for low abundance serum proteins. Proteomics 5: 3183-3192, 2005.

13. Chen YY, Lin SY, Yeh YY, Hsiao HH, Wu CY, Chen ST and Wang AH: A modified protein precipitation procedure for efficient removal of albumin from serum. Electrophoresis 26: 2117-2127, 2005.

14. Amraoui F, Hassani Lahsinoui H, Boussata S, Keijser R, Veenboer GJ, Middeldorp S, van der Post JA, Ris-Stalpers C, Afink GB and van den Born BJ: Placental expression of heparan sulfate 3 -O-sulfotransferase-3A1 in normotensive and pre-eclamptic pregnancies. Placenta 36: 1218-1224, 2015. 
15. Gajewski MM, Alisaraie L and Tuszynski JA: Peloruside, laulimalide, and noscapine interactions with beta-tubulin. Pharm Res 29: 2985-2993, 2012.

16. Hall RE, Horsfall DJ, Stahl J, Vivekanandan S, Ricciardelli C, Stapleton AM, Scardino PT, Neufing P and Tilley WD: Apolipoprotein-D: A novel cellular marker for HGPIN and prostate cancer. Prostate 58: 103-108, 2004.

17. Lau KS and Haigis KM: Non-redundancy within the RAS oncogene family: Insights into mutational disparities in cancer. Mol Cells 28: 315-320, 2009.

18. Chang TW, Chen CC, Chen KY, Su JH, Chang JH and Chang MC: Ribosomal phosphoprotein PO interacts with GCIP and overexpression of P0 is associated with cellular proliferation in breast and liver carcinoma cells. Oncogene 27: 332-338, 2008.

19. Weber-Boyvat M, Zhong W, Yan D and Olkkonen VM: Oxysterol-binding proteins: Functions in cell regulation beyond lipid metabolism. Biochem Pharmacol 86: 89-95, 2013.

20. Olkkonen VM and Levine TP: Oxysterol binding proteins: In more than one place at one time? Biochem Cell Biol 82: 87-98, 2004.

21. Olkkonen VM: OSBP-related protein family in lipid transport over membrane contact sites. Lipid Insights 8 (Suppl 1): S1-S9, 2015.

22. Olkkonen VM and Li S: Oxysterol-binding proteins: Sterol and phosphoinositide sensors coordinating transport, signaling and metabolism. Prog Lipid Res 52: 529-538, 2013.

23. Bondi J, Husdal A, Bukholm G, Nesland JM, Bakka A and Bukholm IR: Expression and gene amplification of primary (A, $\mathrm{B} 1, \mathrm{D} 1, \mathrm{D} 3$, and $\mathrm{E})$ and secondary $(\mathrm{C}$ and $\mathrm{H})$ cyclins in colon adenocarcinomas and correlation with patient outcome. J Clin Pathol 58: 509-514, 2005.

24. Caraglia M, Park MH, Wolff EC, Marra M and Abbruzzese A: eIF5A isoforms and cancer: Two brothers for two functions? Amino Acids 44: 103-109, 2013.

25. Mathews MB and Hershey JW: The translation factor eIF5A and human cancer. Biochim Biophys Acta 1849: 836-844, 2015.

26. Stiborová M, Indra R, Frei E, Kopečková K, Schmeiser HH, Eckschlager T, Adam V, Heger Z, Arlt VM and Martínek V: Cytochrome b5 plays a dual role in the reaction cycle of cytochrome P450 3A4 during oxidation of the anticancer drug ellipticine. Monatshefte Fur Chemie 148: 1983-1991, 2017.

27. Henderson CJ, McLaughlin LA, Finn RD, Ronseaux S, Kapelyukh Y and Wolf CR: A role for cytochrome b5 in the in vivo disposition of anticancer and cytochrome $\mathrm{P} 450$ probe drugs in mice. Drug Metab Dispos 42: 70-77, 2014.
28. Chekhun SV, Lukyanova NY, Shvets YV, Burlaka AP and Buchinska LG: Significance of ferritin expression in formation of malignant phenotype of human breast cancer cells. Exp Oncol 36: 179-183, 2014.

29. Jiang XP and Elliott RL: Decreased iron in cancer cells and their microenvironment improves cytolysis of breast cancer cells by natural killer cells. Anticancer Res 37: 2297-2305, 2007.

30. Dai Z, Zhou SL, Zhou ZJ, Bai DS, Xu XY, Fu XT, Chen Q, Zhao YM, Zhu K, Yu L, et al: Capn4 contributes to tumour growth and metastasis of hepatocellular carcinoma by activation of the FAK-Src signalling pathways. J Pathol 234: 316-328, 2014.

31. Leal MF, Calcagno DQ, Demachki S, Assumpcao PP, Chammas R, Burbano RR and Smith Mde A: Clinical implication of 14-3-3 epsilon expression in gastric cancer. World J Gastroenterol 18: 1531-1537, 2012.

32. Yang Y, Cai J, Yin J, Wang D, Bai Z, Zhang J, Wang K, Yu G and Zhang Z: Inorganic pyrophosphatase (PPA1) is a negative prognostic marker for human gastric cancer. Int J Clin Exp Pathol 8: 12482-12490, 2015.

33. Tang S, Huang W, Zhong M, Yin L, Jiang H, Hou S, Gan P and Yuan Y: Identification Keratin 1 as a cDDP-resistant protein in nasopharyngeal carcinoma cell lines. J Proteomics 75: 2352-2360, 2012 .

34. Jing Z, Yin H, Wang P, Gao J and Yuan L: Centlein, a novel microtubule-associated protein stabilizing microtubules and involved in neurite formation. Biochem Biophys Res Commun 472: 360-365, 2016.

35. Su WP, Chen YT, Lai WW, Lin CC, Yan JJ and Su WC: Apolipoprotein E expression promotes lung adenocarcinoma proliferation and migration and as a potential survival marker in lung cancer. Lung Cancer 71: 28-33, 2011.

36. Hulpke S, Baldauf C and Tampe R: Molecular architecture of the MHC I peptide-loading complex: One tapasin molecule is essential and sufficient for antigen processing. FASEB J 26: 5071-5080, 2012

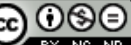

This work is licensed under a Creative Commons Attribution-NonCommercial-NoDerivatives 4.0 International (CC BY-NC-ND 4.0) License. 